\title{
Review of the current treatments for leishmaniases
}

This article was published in the following Dove Press journal:

Research and Reports in Tropical Medicine

26 July 2012

Number of times this article has been viewed

\author{
José Angelo Lauletta \\ Lindoso' \\ Jackson Maurício Lopes \\ Costa ${ }^{2}$ \\ Igor Thiago Queiroz ${ }^{3}$ \\ Hiro Goto \\ 'Instituto de Infectologia Emilio \\ Ribas-SES- SP, São Paulo, São Paulo, \\ Brazil; ${ }^{2}$ Centro de Pesquisas Gonçalo \\ Moniz, Fundação Oswaldo Cruz, \\ Salvador, Bahia, Brazil; ${ }^{3}$ Departament \\ of Infectious Diseases, Faculdade de \\ Medicina, Universidade de São Paulo, \\ São Paulo, Sao Paulo, Brazil; ${ }^{4}$ Instituto \\ de Medicina Tropical de São Paulo, and \\ Faculdade de Medicina, Universidade \\ de São Paulo, Sao Paulo, Sao Paulo, \\ Brazil
}

Correspondence: Hiro Goto Instituto de Medicina Tropical de São Paulo, Av Dr Enéas de Carvalho Aguiar, 470. Prédio II, 05403-000,

São Paulo, SP, Brazil

Tel +55 II 306 I 7023

Fax +55 II $306 \mid 8270$

Email hgoto@usp.br
Abstract: Leishmaniases are vector-borne zoonotic diseases that are prevalent in tropical and subtropical areas in the world, with two million new cases occurring yearly. Visceral and tegumentary forms of leishmaniasis are known. The latter form may present as localized cutaneous or mucosal forms, disseminated, diffuse forms, or leishmaniasis recidiva cutis. Visceral leishmaniasis is caused by parasites of the species Leishmania (Leishmania) donovani and L. (L.) infantum, and tegumentary leishmaniasis is caused by 15 other species, with distinct distributions in the Old and New World. The varied clinical manifestations, the multitude of Leishmania species, and the increasing incidence of HIV coinfection make the diagnosis and treatment of leishmaniases complex. Since there are no solid data relating clinical manifestations, treatment outcomes and Leishmania species the decision regarding the best therapeutic option is almost entirely based on clinical manifestations. Because most of the literature is focused on leishmaniasis in the Old World, in this review we present data on the treatment of New World leishmaniasis in more detail. Ranked therapeutic options, clinical trials, and also observations, even with a restricted number of subjects, on treatment outcome of visceral and different forms of tegumentary leishmaniasis, are presented. Treatment for leishmaniasis in HIVcoinfected patients is addressed as well. Some of these data strongly suggest that the differences in the outcome of the treatment are related to the Leishmania species. Therefore, although it is not possible at most points of care to identify the species causing the infection - a process that requires a well equipped laboratory - the infecting species should be identified whenever possible. More recent approaches, such as the use of immunomodulators and immunotherapy, and the lines for development of new candidate drugs are mentioned.

Keywords: tegumentary, visceral, therapy, HIV

Leishmaniases are vector-borne zoonotic diseases that are caused by various species of protozoa of the genus Leishmania. These pathogens are transmitted by phlebotomine sandflies and infect humans that are exposed to ecosystems where the vectors and reservoirs, either peridomestic or sylvatic, coexist. Anthroponotic cycles have been documented for some species of Leishmania and for defined geographical areas such as that of Leishmania (Leishmania) donovani in the Indian subcontinent and L. (L.) major in Afghanistan. Leishmaniases are prevalent in tropical and subtropical areas, with two million new cases occurring yearly. ${ }^{1-3}$

Visceral and tegumentary forms of leishmaniasis are known. Visceral leishmaniasis (VL) is caused by $L$. (L.) donovani in the Indian subcontinent and East Africa and by L. (L.) infantum in other parts of Asia, Europe, Africa and the New World (where it was formerly referred to as $L$. (L.) chagasi). Tegumentary leishmaniasis (TL) is caused by 
approximately 15 species of parasites: $L$. (L.) major, L. (L.) tropica, L. (L.) aethiopica and sometimes $L$. (L.) infantum in the Old World and L. (Viannia) braziliensis, L. (L.) amazonensis, L. (V.) guyanensis, L. (V.) panamensis, L. (L.) mexicana, L. (L.) pifanoi, L. (L.) venezuelensis, L. (V.) peruviana, L. (V.) shawi, and L. (V.) lainsoni in the New World. ${ }^{3,4}$ Among species causing TL, different species of subgenus Viannia and L. (L.) amazonensis (subgenus Leishmania) are found from Mexico to Argentina, and the largest variety is present in Brazil, mainly in the Amazon region. L. (L.) mexicana is present in Mexico and other Central American countries.

Patients with active VL present with fever, hepatosplenomegaly, pancytopenia, hypergammaglobulinemia, and severe weight loss. The manifestations of TL are varied and are classified as localized cutaneous or mucosal forms, disseminated, diffuse forms, or leishmaniasis recidiva cutis; ${ }^{5}$ some of these forms are related to particular species (Table 1). The localized cutaneous form is the initial lesion in most cases, and the progression to other forms depends on the species of Leishmania involved and on the host response. ${ }^{5}$

The varied clinical manifestations, the multitude of Leishmania species, and the increasing incidence of HIV coinfection make the diagnosis and treatment of leishmaniases complex. The fact that there are no solid data relating

Table I Clinical manifestations of leishmaniasis and related Leishmania species

\begin{tabular}{lll}
\hline $\begin{array}{l}\text { Clinical } \\
\text { manifestation }\end{array}$ & Leishmania species & $\begin{array}{l}\text { Geographical } \\
\text { area }\end{array}$ \\
\hline Localized cutaneous & L. (L.) tropica & Old World \\
leishmaniasis & L. (L.) major & Old World \\
& L. (L.) aethiopica & Old World \\
& L. (L.) amazonensis & New World \\
of subgenus Viannia & New World \\
Disseminated & L. (V.) braziliensis & New World \\
cutaneous leishmaniasis & L. (L.) amazonensis & New World \\
Diffuse cutaneous & L. (L.) mexicana & New World \\
leishmaniasis & L. (L.) amazonensis & New World \\
& L. (L.) aethiopica & Old World \\
Leishmaniasis & L. (L.) tropica & Old World \\
recidivacutis & L. (V.) braziliensis & New World \\
& L. (L.) amazonensis & New World \\
Mucosal leishmaniasis & L. (V.) panamensis & New World \\
& L. (V.) braziliensis & New World \\
& L. (V.) panamensis & New World \\
& L. (V.) guyanensis & New World \\
& L. (L.) amazonensis & New World \\
& L. (L.) major & Old World \\
Visceral leishmaniasis & Leishmania (L.) donovani & Old World, \\
& & except Europe \\
& Leishmania (L.) infantum & Europe, Africa, \\
& & and New World \\
\hline
\end{tabular}

clinical manifestations, treatment outcomes and Leishmania species the decision regarding the best therapeutic option is still based almost entirely on clinical manifestations. Although it is not possible at most points of care to identify the species causing the infection - a process that requires a well equipped laboratory - the infecting species should be identified whenever possible, because differences in treatment outcomes have been reported for localized cutaneous leishmaniasis (CL) caused by L. (V.) braziliensis and L. (V.) guyanensis. ${ }^{6-8}$

Because most of the literature is focused on leishmaniasis in the Old World, herein we present data on the treatment of New World leishmaniasis in more detail.

\section{Compounds in current use for the treatment of leishmaniasis Pentavalent antimonials}

Over the past 70 years, the first-choice drugs for the treatment of leishmaniasis have been pentavalent antimony compounds, which are available in two formulations, methylglucamine antimoniate and sodium stibogluconate. ${ }^{9}$ The mechanism of action of pentavalent antimonials is still not well understood, but the drugs inhibit the activity of the glycolytic and oxidative pathways of fatty acids in amastigotes. ${ }^{10}$ The most frequent side effects of pentavalent antimonials are arthralgia, myalgia, anorexia, headache, fever, vomiting, and dizziness. These drugs are toxic to the heart, kidneys, liver, and pancreas, and this toxicity represents an important limitation in the use of these drugs by pregnant women, the elderly, and individuals with cardiac disease, renal disease, or liver alterations. ${ }^{5}$

\section{Amphotericin B}

Amphotericin B, a polyenic antibiotic with leishmanicidal activity, acts both on promastigotes and amastigotes and targets ergosterol in the surface membrane of the parasite, leading to increased permeability and the influx of ions. ${ }^{11}$ There are four formulations of amphotericin B for clinical use: deoxycholate amphotericin B, liposomal amphotericin B, amphotericin colloidal dispersion, and amphotericin B lipid complex. ${ }^{5,10}$ Deoxycholate amphotericin B causes more severe adverse effects that include nausea, vomiting, fever, hypokalemia, renal failure, anemia, and heart problems. The cardiotoxicity, nephrotoxicity, and hypokalemia induced by this drug formulation and its intravenous delivery restrict its use to the hospital environment. ${ }^{5,12}$ Liposomal amphotericin B is more expensive; however, it reaches higher peak plasma levels, exhibits a shorter circulating half-life, and 
reaches higher concentrations in the liver and spleen, with much less toxicity than conventional amphotericin $\mathrm{B}$. The lipid component drives the drug into the intracellular milieu, favoring the interaction with ergosterol of the parasite over host cholesterol. ${ }^{13}$

\section{Pentamidine}

Pentamidine is a dibenzamidine that interferes with the synthesis of Leishmania DNA acting on the kinetoplast and on the mitochondrial membrane, leading to the death of the parasite. The primary adverse effects are hypotension, myalgia, abscess at the injection site, hypoglycemia, and diabetes mellitus. ${ }^{5,8,10}$

\section{Miltefosine}

Initially developed for the treatment of cancer, miltefosine inhibits phospholipid and sterol biosynthesis and both in vitro and in vivo Leishmania. The limitation for its use is its toxicity to the gastrointestinal, hepatic, and renal systems. It is also teratogenic, which restricts its use in pregnant women.,

\section{Paromomycin}

Paromomycin is a broad spectrum aminoglycoside antibiotic that was found to have leishmanicidal activity in the 1960s. The main side effects are ototoxicity and local pain upon injection. ${ }^{8,10}$ The drug supposedly affects plasma membrane fluidity, interferes with ribosomes and mitochondrial membrane potential, inhibiting respiration. ${ }^{14}$

\section{Imidazoles/triazoles (ketoconazole, fluconazole, itraconazole)}

These antifungal drugs include two distinct classes of compounds: imidazoles (eg, ketoconazole) and triazoles (eg, fluconazole and itraconazole). These two classes of compounds share the same antifungal spectrum and the same mechanism of action, but the metabolism of triazoles is slower. In addition, triazoles interfere less with sterol synthesis in humans and are thus less toxic than imidazoles. A great advantage of the azoles used in leishmaniases is their oral use and lower toxicity relative to pentavalent antimonials. ${ }^{15}$

\section{Treatment of leishmaniasis}

There are few drugs available for the treatment of leishmaniasis as listed in the Table 2 .

\section{$\mathrm{VL}$}

VL is caused by two distinct species of Leishmania. Concerning clinical manifestations, only $L$. (L.) donovani infection can evolve into post-kalazar dermal leishmaniasis
(PKDL), which is characterized by the appearance of cutaneous lesions containing parasites in the period after treatment of VL. ${ }^{16}$

The drug used to treat active VL is chosen based on risk factors, patient characteristics, geographical area, and Leishmania species.

Pentavalent antimonials (sodium stibogluconate or meglumine antimoniate) are the first-line drugs used to treat VL. ${ }^{17}$ In the New World, mainly in Brazil, the efficacy of these drugs is higher than $90 \%,{ }^{18}$ whereas treatment failure is approximately $60 \%$ in Bihar, India, and in Nepal. ${ }^{19,20}$ When treatment failure occurs or when there are restrictions, alternative drugs are used.

The second-choice drugs are the different formulations of amphotericin B, which have been shown to be effective against different species of Leishmania from different geographical areas, exhibiting high efficacy and low toxicity. ${ }^{19,21}$ In the Indian subcontinent and Europe, liposomal amphotericin B has been used as a first-line drug due to the resistance to antimonials in some areas; ${ }^{20}$ liposomal amphotericin B is used in the United States of America because it is the only treatment approved by the Food and Drug Administration. Recently a single-dose treatment with liposomal amphotericin B was tried in India, with $95 \%$ cure. ${ }^{22}$ In the New World, mainly in Brazil, amphotericin B has been used successfully to treat VL in particular situations, primarily in older patients, children, transplant recipients, and patients with comorbidities such as diabetes and HIV infection. ${ }^{18}$

Miltefosine, another alternative drug, is used to treat VL in the Indian subcontinent, ${ }^{23,24}$ where it exhibits high efficacy; it is used primarily to treat moderate VL. In contrast, in the New World, miltefosine was shown to be less effective than a pentavalent antimonial in a clinical trial that had to be discontinued (personal communication). Systemic paromomycin is a new option to treat VL in the Indian subcontinent and exhibits high efficacy. ${ }^{25,26}$ In East Africa, the efficacy of paromomycin was found to be lower, and therefore it is recommended that a higher dose be used or that the drug be used in combination with a pentavalent antimonial. ${ }^{27}$ There has been no trial with paromomycin in the New World to date.

The evaluation of clinical recovery during and after treatment is based on the remission of fever, the reduction of splenomegaly and hepatomegaly, and the improvement of hematological disturbances. ${ }^{3}$ There is no consensus regarding the parasitological or immunological methods that should be used to evaluate treatment success, but such methods are used in some centers to determine whether patients have been cured. The cure rate is typically $90 \%-95 \%$, and the 
Table 2 Medicines with doses used to treat tegumentary and visceral leishmaniases ${ }^{\mathrm{a}}$

\begin{tabular}{|c|c|c|c|c|c|}
\hline & Pentavalent antimonials & $\begin{array}{l}\text { Amphotericin B } \\
\text { deoxycholate }\end{array}$ & $\begin{array}{l}\text { Liposomal } \\
\text { amphotericin B }\end{array}$ & $\begin{array}{l}\text { Pentamidine } \\
\text { isethionate }\end{array}$ & Miltefosine \\
\hline Localized & $10-20 \mathrm{mg} / \mathrm{Sb}^{+5} / \mathrm{kg} /$ day (iv or im) & I mg/kg/day (iv) & & $4 \mathrm{mg} / \mathrm{kg} /$ day $(\mathrm{im})$ & $2.5 \mathrm{mg} / \mathrm{kg}$ (oral) \\
\hline $\begin{array}{l}\text { cutaneous } \\
\text { leishmaniasis }\end{array}$ & $10-20$ days & Total dose: $1.0-1.5 \mathrm{~g}$ & & Maximum dose: $2 \mathrm{~g}$ & $\begin{array}{l}28 \text { days to treat } \\
\text { L. mexicana }\end{array}$ \\
\hline Disseminated & $20 \mathrm{mg} / \mathrm{Sb}^{+5} / \mathrm{kg} /$ day (iv or im) & I mg/kg/day (iv) & & $4 \mathrm{mg} / \mathrm{kg} /$ day $(\mathrm{im})$ & \\
\hline $\begin{array}{l}\text { cutaneous } \\
\text { leishmaniasis }\end{array}$ & 28 days & Total dose: $1.0-1.5 \mathrm{~g}$ & & Maximum dose: $2 \mathrm{~g}$ & \\
\hline Diffuse & $20 \mathrm{mg} / \mathrm{Sb}^{+5} / \mathrm{kg} /$ day (iv or im) & & & Not used & Not used \\
\hline $\begin{array}{l}\text { cutaneous } \\
\text { leishmaniasis }\end{array}$ & 28 days & & & & \\
\hline $\begin{array}{l}\text { Leishmaniasis } \\
\text { recidiva cutis }\end{array}$ & $\begin{array}{l}15-20 \mathrm{mg} \mathrm{Sb} b^{+5} / \mathrm{kg}_{\text {(iv or im) }} \\
\text { per day for } 28 \text { days }^{\mathrm{b}}\end{array}$ & & & & \\
\hline Mucosa & $20 \mathrm{mg} / \mathrm{Sb}^{+5} / \mathrm{kg} /$ day (iv or im) & I mg/kg/day (iv) & $2-3 \mathrm{mg} / \mathrm{kg} /$ day (iv) & Not used & $2.5 \mathrm{mg} / \mathrm{kg}$ (oral) \\
\hline leishmaniasis & 30 days & Total dose: $2.0-2.5 \mathrm{~g}$ & Total dose: $40-60 \mathrm{mg} / \mathrm{kg}$ & & 28 days $^{c}$ \\
\hline Visceral & $20 \mathrm{mg} / \mathrm{Sb}^{+5} / \mathrm{kg} /$ day (iv or im) & $0.75-1.00 \mathrm{mg} / \mathrm{kg} /$ day (iv) & $3-4 \mathrm{mg} / \mathrm{kg} /$ day (iv) & Not used & $2.5 \mathrm{mg} / \mathrm{kg}$ (oral) \\
\hline leishmaniasis & for 28 days $^{d}$ & $15-20$ doses & Total dose: $15-24 \mathrm{mg} / \mathrm{kg}$ & & 28 days $^{\mathrm{e}}$ \\
\hline
\end{tabular}

Notes: ${ }^{a}$ Doses and time of treatment were based on WHO recommendation from 20 I0; bin case of no response to the usual dose of $\mathrm{Sb}^{+5}$, $\mathrm{Sb}^{+5} \mathrm{plus} \mathrm{allopurinol}^{20} \mathrm{mg} / \mathrm{kg}$ for

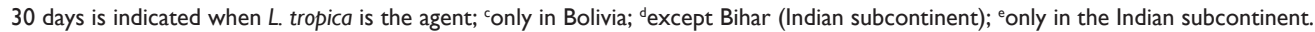

Abbreviations: $\mathrm{Sb}^{+5}$, pentavalent antimonial; iv, intravenous; im, intramuscular.

endpoint of the follow-up period to assess relapse is 6 months after treatment. ${ }^{3}$ For relapses, the second-choice drugs and combinations of different drugs are used. Another complication is the appearance of PKDL in 5\%-10\% of patients after the apparent cure of VL caused by $L$. (L.) donovani ${ }^{16}$ the appearance of PKDL is not considered a relapse, and PKDL is treated with the same drug as used to treat VL but for an extended duration. ${ }^{3}$

The recommendation of HIV testing in patients with recent VL diagnosis should be emphasized because the treatment response in coinfected patients is poorer than in noncoinfected patients.

\section{CL of the Old World}

In the Old World, CL caused by $L$. (L.) major has been treated with local paromomycin/methylbenzethonium chloride ointment, intralesional antimonials, and cryotherapy or thermotherapy when the lesion is small and not disfiguring or disabling, and when the patient is not immunosuppressed. When the disease is caused by the species $L$. (L.) tropica, $L$. (L.) aethiopica, or $L$.(L.) infantum, the preferred local treatment is intralesional antimonials alone or thermotherapy or cryotherapy alone. When systemic treatment is required, the choices are fluconazole or pentavalent antimonials plus pentoxifylline. ${ }^{3,28}$ For the treatment of leishmaniasis recidiva cutis caused by $L$. (L.) tropica, the use of pentavalent antimonials plus oral allopurinol is recommended. For the treatment of diffuse CL caused by $L$. (L.) aethiopica, pentavalent antimonials plus intramuscular paromomycin are used. ${ }^{3,28}$

\section{CL of the New World}

Local treatment in clinical trials using paromomycin in different formulations have shown varied results, from a $64 \%$ cure rate in Colombia ${ }^{29}$ to an $88.6 \%$ cure rate in a doubleblind study in Guatemala; the difference in the cure rates may be related to the Leishmania species that are prevalent in each area. Currently, the topical treatment of CL in the New World is not recommended, except in cases of infection with $L$. (L.) mexicana or in areas where the severe forms of the disease are very rare, as in Venezuela and Colombia. ${ }^{30}$

The use of pentavalent antimonials resulted in a $5 \%$ therapeutic failure rate among cases of CL caused by L. (V) braziliensis. ${ }^{29}$ It was observed that $7 \%, 16 \%$, and $39 \%$ of patients were refractory to treatment in Brazil, Bolivia, and Colombia, respectively; the infecting species were not identified in these studies. ${ }^{31,32} \mathrm{~A}$ randomized study that compared drugs showed that $40 \%$ of patients with CL caused by $L$. (V.) braziliensis who were treated exclusively with an antimonial required more than two or three courses of treatment to achieve a cure ${ }^{33,34}$ Although spontaneous remission has been reported in the literature, it is infrequent among cases of CL caused by $L$. (V.) braziliensis, and there is a risk that the patient will develop mucosal leishmaniasis (ML) if no treatment is given. Costa et $\mathrm{al}^{35}$ reported the results of clinical evaluations carried out over a period of 14 years in field clinics in the communities of Três Braços and Corte de Pedra, Bahia, Brazil involving 1416 patients with TL caused predominantly by $L$. (V.) braziliensis. Most of these patients received antimonial treatment, but 16 male patients refused treatment, and six pregnant female 
patients were not treated. During the patient follow-up period of 4-12 years, the observed healing time was 6 months for nine patients $(40.9 \%)$; complete healing after 12 months was observed for19 patients (86.3\%), and no healing after 12 months was observed in three $(13.6 \%)$ cases. ${ }^{35}$

In some studies, liposomal amphotericin B has been used to treat patients with CL caused by L.(V.) guyanensis, ${ }^{36}$ L. (V.) braziliensis, ${ }^{37}$ L. (L.) infantum, ${ }^{38}$ or L. (L.) aethiopica.$^{39}$ However, larger studies are needed to assess the effectiveness of amphotericin B for the treatment of CL. ${ }^{40}$

Pentamidine has been used successfully in areas endemic for CL due to L. (V.) guyanensis (4 mg/kg on days 1 and 4). ${ }^{41}$ The rate of treatment failure depends on when the treatment was started; a 5\% failure rate was observed when the treatment was started within the first month of disease, and a $25 \%$ failure rate was observed when treatment was started later. ${ }^{41}$ In areas where infections are caused by $L$. (V.) braziliensis, L. (V.) shawi and L. (V.) guyanensis, the use of three intramuscular doses of $4 \mathrm{mg} / \mathrm{kg}$ on days 1,3 , and 5 is recommended, not exceeding a maximum dose of $300 \mathrm{mg} /$ day. The effectiveness of this regimen was similar to that of 20-day antimonial treatment, reaching a 70\%-75\% cure rate; a lower dose and a shorter duration resulted in a $35 \%$ cure rate rer $^{42}$ liposomal amphotericin B.

Miltefosine was used initially in 2005 in Colombia for the treatment of TL. ${ }^{15}$ In Bolivia, oral miltefosine ( $2.5 \mathrm{mg} / \mathrm{kg} / 28$ days) was compared with an intramuscular antimonial ( $20 \mathrm{mg} / \mathrm{kg} / 20$ days) to treat TL caused by $L$. (V.) braziliensis, ${ }^{43}$ and the cure rates after 6 months were $88 \%$ (36/41) and 94\% (15/16), respectively. In Colombia, where $L$. $(V$.) panamensis is common, the same dose of oral miltefosine resulted in a $91 \%$ cure rate, similar to the cure rate for antimonials, whereas the cure rate of the placebo group was $38 \% .{ }^{44}$ In Guatemala, where L. (V.) braziliensis and L. (L.) mexicana predominate, the cure rate for miltefosine was only $53 \%$, significantly lower than the cure rate for antimonials. ${ }^{44}$ Thus, further studies are needed to specifically assess the value of miltefosine in the treatment of TL in the New World and to investigate the activity of miltefosine against different Leishmania species.

Regarding azoles, studies in Guatemala $(\mathrm{N}=120$ patients $)$ and Belize $(\mathrm{N}=8)$ assessed the efficacy of a 28-day regimen of oral $600 \mathrm{mg}$ ketoconazole and found a lower cure rate (30\% and $25 \%$, respectively) among patients infected with L.(V.) braziliensis compared with the rate among patients infected with $L$. (L.) mexicana ( $89 \%$ and $100 \%$, respectively). Moreover, among patients infected with $L$. (V) panamensis, ketoconazole seemingly has a performance similar to that of antimonials. ${ }^{45}$ However, the interpretation of these data should take into account the fact that CL caused by $L$. (L.) mexicana and L.(V.) panamensis has a high spontaneous cure rate. $^{45}$

Drug combinations that include pentavalent antimonials have been recommended in an attempt to increase the efficacy, reduce the dose, and decrease the prevalences of side effects and therapeutic failure.

\section{ML}

The frequency of ML varies according to the Leishmania species involved and to the geographical region. Andean countries have one of the highest frequencies of ML, with an average incidence of $7.1 \% .{ }^{30}$ Only systemic drugs are used for the treatment of ML. The cure rates are variable and depend on the geographical area, the Leishmania species involved, and the drug used for treatment. ${ }^{46,47}$

Pentavalent antimonials are the most used drugs to treat ML around the world. Different doses have been evaluated, and doses other than the recommended dose are occasionally used; however, the decision to use a different dose must be based on structured studies within the same area and with the same Leishmania species. ${ }^{48,49}$ The cure rate after treatment using pentavalent antimonials varies from $30 \%$ to $90 \%{ }^{50}$

Because some reports using liposomal amphotericin B formulations for the treatment of ML have shown excellent results, liposomal amphotericin B can be an alternative treatment; however, the optimal doses for the treatment of ML have not been completely defined. ${ }^{51}$ The use of pentamidine has been evaluated in Brazil, and healing was observed in nine $(90 \%)$ of the ten patients who received $2140 \mathrm{mg}$ and were followed up for 7.7 months. ${ }^{50}$ Although the results are promising, few studies have been conducted to confirm this drug's effectiveness due to its severe adverse effects and the discontinuity of drugs.

Miltefosine was used to treat ML in Bolivia, showing cure rates of $71 \%$ and $74 \%$ in patients treated for four ${ }^{52}$ and $\operatorname{six}^{53}$ weeks, respectively. However, the secure rates are lower than that for amphotericin B but similar to that for pentavalent antimonials.

\section{Criteria of cure and follow up}

There is no consensus on the criteria of cure in the literature, and this fact results in some controversial data seen in reported cure rate upon treatment. It would be desirable to have standardized criteria to be used in different studies based on clinical, parasitological parameters and the follow up time. In Brazil only the clinical criteria are considered, 
since other parameters are not satisfactory for this purpose. $\mathrm{CL}$ is considered cured when total epithelialization of the lesion and absence of any induration at the base of the ulcer are achieved within 3 months of treatment. ML is considered cured when regression of all clinical signs is achieved within 6 months of treatment. When these criteria are not reached, it is considered a relapse. ${ }^{54}$

\section{Leishmania/HIVcoinfection}

HIV is present worldwide and is gradually spreading into areas endemic for leishmaniasis, leading to the appearance of Leishmania/HIV coinfection. The interaction of these two infections accelerates both disease processes, worsening the prognosis of both. ${ }^{3,55,56}$

More data concerning treatment are available for coinfected patients with VL, mainly from the Old World. Therefore, more studies of patients with TL are needed because this form is more frequent in the New World, accounting for approximately $63 \%$ of coinfected patients. ${ }^{57}$

For the treatment of VL in HIV-infected patients, the same drugs as used to treat noncoinfected patients are used. Coinfected patients more often experience adverse events, treatment failures, and relapses than immunocompetent individuals. ${ }^{3,55,56}$ Cardiotoxicity, nephrotoxicity, and pancreatic damage are responsible for interruptions in treatment. ${ }^{56,58,59}$

Varied cure rate has been observed in HIV-coinfected patients treated with pentavalent antimonials. In Ethiopia cure rate was 58.3\% ${ }^{60}$ and 58.6\%, ${ }^{61}$ while in Brazil it reached $68.4 \%$ (personal data). When used as rescue treatment upon treatment failure with liposomal amphotericin B presented, the cure rate reaches $83 \%$. However, in this group, high mortality was observed, probably due to the adverse effects of pentavalent antimonials. ${ }^{59}$

Liposomal amphotericin B in different doses has been used to treat VL in HIV-infected patients. When liposomal amphotericin B was used at a total dose of $30 \mathrm{mg} / \mathrm{kg}$, an initial cure rate of $59.8 \%$ was observed. ${ }^{59}$ In India, using a total dose of $20-24 \mathrm{mg} / \mathrm{kg}$, the cure rate was $74.5 \%,{ }^{62}$ and in Brazil using the same dose it reached 63\% (personal data).

Miltefosine has been used in Ethiopia, and the cure rate was $46 \%$ in HIV-coinfected patients. ${ }^{61}$

Systemic treatment with paromomycin exhibited good efficacy among HIV-positive patients with VL in the Indian subcontinent (94\%) and Ethiopia; however, the efficacy of this treatment in Sudan was low. The efficacy and safety of systemic paromomycin are still unknown in other areas. ${ }^{63}$
Pentamidine was previously used for the treatment of VL, but due to resistance in the Indian subcontinent, its use was abandoned. ${ }^{63}$ Currently, the use of pentamidine as a prophylactic agent is accepted because it is easy to administer, causes few adverse events, and exhibits minimal interference with antiretroviral therapy. ${ }^{3}$ However, clinical trials are still needed to demonstrate the efficacy of pentamidine as a secondary prophylactic agent in HIV-positive patients.

The cure rate in VL patients coinfected with HIV is always lower than in HIV-negative patients, independent of whether they are treated with pentavalent antimonials or liposomal amphotericin B.

Because it has been reported that the efficacy of liposomal amphotericin B is limited, it has been proposed that higher doses be used to prevent resistance and to achieve a better cure rate; ${ }^{21}$ high doses can be used because of the low frequency of adverse events such as nephrotoxicity. ${ }^{55,64}$

Antiretroviral treatment, which promotes increases in the CD4+ T cell count and decreases in the viral load in HIVpositive patients, is suggested to have an anti-Leishmania effect. ${ }^{58}$ Even when the CD4+ T cell count is restored, secondary prophylaxis for VL is necessary for a long period to prevent relapses in coinfected patients. The reduction of the incidence of VL, the high survival rate of patients, high relapse rates, and possible immune reconstitution inflammatory syndrome are some impacts of antiretroviral therapy on VL. ${ }^{3}$ Further, combining antiretroviral therapy with antiLeishmania drugs seemingly prevents resistance, increases tolerance and efficacy, and reduces the duration and cost of VL treatment. ${ }^{65}$

Among patients with TL, poorer responses to standard treatment and frequent relapses have been reported. ${ }^{66,67}$ The cure rate of TL is variable and depends on immune status and the Leishmania species that is present. Recently, Guerra et $\mathrm{l}^{68}$ showed that the poor response to pentavalent antimonial treatment in co-infected patients was related to the high prevalence of $L$. (V.) guyanensis in the Amazon region. In the Old World, poor responses to pentavalent antimonials have been observed among HIV-infected patients with CL caused by $L$. (L.) tropica $^{65}$ Independent of the Leishmania species, poor response to treatment is observed among HIV-infected patients, especially among those who are severely immunosuppressed.

\section{Future of the treatment for leishmaniasis}

To improve the treatment, different approaches have been evaluated, which include the use of immunomodulators and immunotherapy. For these approaches, basic information on 
the immune response and its progression during the disease course in leishmaniases patients is important.

During active $\mathrm{CL}$, there is a predominance of $\mathrm{CD}^{+} \mathrm{T}$ cell response, and upon treatment the production of interferongamma increases while that of IL-10 decreases. ${ }^{69}$ However, in ML, a high level of tumor necrosis factor (TNF)- $\alpha$ is observed during active lesion, which decreases with therapy. ${ }^{70}$ Therefore, cytokines and inflammatory response modulators have been used in combination with other drugs, showing promising results. Pentoxifylline, an inhibitor of TNF- $\alpha$, and imiquimod, an activator of Toll-like receptor 7 and a mediator of inflammatory cytokine production, have been used in association with antimonials to treat TL showing, respectively, reduction in the time to cure ${ }^{71,72}$ or increase of cure rate to $90 \%$ in patients refractory to antimonials. ${ }^{73,74}$ Association of inteferon- $\gamma$ with antimonials is also effective in curing TL patients presenting resistance to antimonials. ${ }^{75}$ Topical recombinant human granulocyte-macrophage colony-stimulating factor in combination with antimonials was also shown to reduce the healing time $50 \%{ }^{76}$

As immunotherapy, Leishmania antigen, whole promastigote preparations, recombinant Leishmania antigens as Leish-111f, alone or in combination with adjuvants such as bacillus Calmette-Guerin (BCG) and monophosphoryl lipid $\mathrm{A},{ }^{77}$ have shown promising results. ${ }^{78}$ Immunotherapy in association with drugs is an option to preclude toxicity and emergence of resistance related to some drugs. Only in Venezuela is immunotherapy with whole promastigote preparation with $\mathrm{BCG}$ as adjuvant in current use to treat $\mathrm{CL}{ }^{79,80}$

The development of new candidate drugs is in progress, following mainly three lines. One focuses on plants as a source of anti-protozoal molecules, the other explores metabolic pathways of the parasite to find the target and to develop synthetic compounds, ${ }^{81}$ and the more immediate approach is the repositioning of the medicines already on the market for other purposes. From the latter approach, amphotericin $\mathrm{B}$, miltefosine, and pentoxifyilline, for example, have been previously developed, and presently, tamoxifen, a drug used for breast cancer, is being studied. ${ }^{82}$

\section{Acknowledgments}

Financial support of Laboratorio de Investigação Médica (LIM-38) do Hospital das Clínicas da Faculdade de Medicina, USP and Conselho Nacional de Pesquisa (research fellowship to $\mathrm{HG})$.

\section{Disclosure}

The authors report no conflicts of interest in this work.

\section{References}

1. Desjeux P. Leishmaniasis: current situation and new perspectives. Comp Immunol Microbiol Infect Dis. 2004;27(5):305-318.

2. Faulde M, Schrader J, Heyl G, Amirih M. Differences in transmission seasons as an epidemiological tool for characterization of anthroponotic and zoonotic cutaneous leishmaniasis in northern Afghanistan. Acta Trop. 2008;105(2):131-138.

3. World Health Organization (WHO). Control of Leishmaniases: report of a meeting of the WHO Expert Committee. Geneva: WHO; 2010.

4. Banuls AL, Hide M, Prugnolle F. Leishmania and the leishmaniases: a parasite genetic update and advances in taxonomy, epidemiology and pathogenicity in humans. Adv Parasitol. 2007;64:1-109.

5. Goto H, Lindoso JA. Current diagnosis and treatment of cutaneous and mucocutaneous leishmaniasis. Expert Rev Anti Infect Ther. 2010;8(4): 419-433.

6. Arevalo J, Ramirez L, Adaui V, et al. Influence of Leishmania (Viannia) species on the response to antimonial treatment in patients with American tegumentary leishmaniasis. J Infect Dis. 2007;195(12):1846-1851.

7. Romero GA, Guerra MV, Paes MG, Macedo VO. Comparison of cutaneous leishmaniasis due to Leishmania (Viannia) braziliensis and L. (V.) guyanensis in Brazil: therapeutic response to meglumine antimoniate. Am J Trop Med Hyg. 2001;65(5):456-465.

8. Seifert K. Structures, targets and recent approaches in anti-leishmanial drug discovery and development. Open Med Chem J. 2011;5:31-39.

9. Marsden PD, Jones TC. Clinical manifestations, diagnosis and treatment of cutaneous leishmaniasis. In: Chang K-P, Bray RS, editor. Amsterdam: Elsevier Science; 1985.

10. Croft SL, Seifert K, Yardley V. Current scenario of drug development for leishmaniasis. Indian J Med Res. 2006;123(3):399-410.

11. Ellis M, Bernsen R, Ali-Zadeh H, et al. A safety and feasibility study comparing an intermittent high dose with a daily standard dose of liposomal amphotericin B for persistent neutropenic fever. $J$ Med Microbiol. 2009;58(Pt 11):1474-1485.

12. Marsden PD. Personal experience with diagnostic and therapeutic aspects of human Leishmania (Viannia) braziliensis in Tres Bracos. Memorias do Instituto Oswaldo Cruz. 1994;89(3):485-487.

13. Berman JD. Human leishmaniasis: clinical, diagnostic, and chemotherapeutic developments in the last 10 years. Clin Infect Dis. 1997;24(4): 684-703.

14. Maarouf M, de Kouchkovsky Y, Brown S, Petit PX, Robert-Gero M. In vivo interference of paromomycin with mitochondrial activity of Leishmania. Exp Cell Res. 1997;232(2):339-348.

15. Mitropoulos P, Konidas P, Durkin-Konidas M. New World cutaneous leishmaniasis: updated review of current and future diagnosis and treatment. J Am Acad Dermatol. 2010;63(2):309-322.

16. Zijlstra EE, Musa AM, Khalil EA, el-Hassan IM, el-Hassan AM. Post-kala-azar dermal leishmaniasis. Lancet Infect Dis. 2003;3(2): 87-98.

17. Murray HW, Berman JD, Davies CR, Saravia NG. Advances in leishmaniasis. Lancet. 2005;366(9496):1561-1577.

18. Brazil. Ministry of Health. Secretary of Health Surveillance. Visceral leishmaniasis, clinical recommendations for the reduction of mortality. 2nd ed.- Brasília. Publisher: Ministry of Health, 78 p. 2009. Available at portal.saude.gov.br/portal/arquivos/.../lv_reducao_letalidade_web.pdf

19. Alvar J, Croft S, Olliaro P. Chemotherapy in the treatment and control of leishmaniasis. Adv Parasitol. 2006;61:223-274.

20. Sundar S. Drug resistance in Indian visceral leishmaniasis. Trop Med Int Health. 2001;6(11):849-854.

21. Bern C,Adler-Moore J, Berenguer J, et al. Liposomal amphotericin B for the treatment of visceral leishmaniasis. Clin Infect Dis. 2006;43(7): 917-924.

22. Sundar S, Chakravarty J, Agarwal D, Rai M, Murray HW. Single-dose liposomal amphotericin B for visceral leishmaniasis in India. $N$ Engl J Med. 2010;362(6):504-512.

23. Berman JD. Development of miltefosine for the leishmaniases. Mini Rev Med Chem. 2006;6(2):145-151.

24. Croft SL, Sundar S, Fairlamb AH. Drug resistance in leishmaniasis Clin Microbiol Rev. 2006;19(1):111-126. 
25. Sundar S, Chakravarty J. Paromomycin in the treatment of leishmaniasis. Expert Opin Investig Drugs. 2008;17(5):787-794.

26. Davidson RN, den Boer M, Ritmeijer K. Paromomycin. Trans R Soc Trop Med Hyg. 2009;103(7):653-660.

27. Hailu A, Musa A, Wasunna M, et al. Geographical variation in the response of visceral leishmaniasis to paromomycin in East Africa: a multicentre, open-label, randomized trial. PLoS Negl Trop Dis. 2010;4(10):e709.

28. Gonzalez U, Pinart M, Reveiz L, Alvar J. Interventions for Old World cutaneous leishmaniasis. Cochrane Database Syst Rev. 2008;4: CD005067.

29. Soto JM, Toledo JT, Gutierrez P, et al. Treatment of cutaneous leishmaniasis with a topical antileishmanial drug (WR279396): phase 2 pilot study. Am J Trop Med Hyg. 2002;66(2):147-151.

30. Davies CR, Reithinger R, Campbell-Lendrum D, Feliciangeli D, Borges R, Rodriguez N. The epidemiology and control of leishmaniasis in Andean countries. Cad Saude Publica. 2000;16(4):925-950.

31. Oliveira-Neto MP, Schubach A, Mattos M, Goncalves-Costa SC, Pirmez C. A low-dose antimony treatment in 159 patients with American cutaneous leishmaniasis: extensive follow-up studies (up to 10 years). Am J Trop Med Hyg. 1997;57(6):651-655.

32. Palacios R, Osorio LE, Grajalew LF, Ochoa MT. Treatment failure in children in a randomized clinical trial with 10 and 20 days of meglumine antimonate for cutaneous leishmaniasis due to Leishmania viannia species. Am J Trop Med Hyg. 2001;64(3-4):187-193.

33. Rocha PN, Almeida RP, Bacellar O, et al. Down-regulation of Th1 type of response in early human American cutaneous leishmaniasis. J Infect Dis. 1999;180(5):1731-1734.

34. Santos JB, de Jesus AR, Machado PR, et al. Antimony plus recombinant human granulocyte-macrophage colony-stimulating factor applied topically in low doses enhances healing of cutaneous Leishmaniasis ulcers: a randomized, double-blind, placebo-controlled study. $J$ Infect Dis. 2004;190(10):1793-1796.

35. Costa JM, Vale KC, Franca F, et al. Spontaneous healing of leishmaniasis caused by Leishmania viannia braziliensis in cutaneous lesions. Rev Soc Bras Med Trop. 1990;23(4):205-208.

36. Amato VS, Rabello A, Rotondo-Silva A, et al. Successful treatment of cutaneous leishmaniasis with lipid formulations of amphotericin B in two immunocompromised patients. Acta tropica. 2004;92(2):127-132.

37. Brown M, Noursadeghi M, Boyle J, Davidson RN. Successful liposomal amphotericin B treatment of Leishmania braziliensis cutaneous leishmaniasis. Br J Dermatol. 2005;153(1):203-205.

38. Paradisi A, Capizzi R, Zampetti A, et al. Atypical multifocal cutaneous leishmaniasis in an immunocompetent patient treated by liposomal amphotericin B. J Infect. 2005;51(5):e261-e264.

39. Rapp C, Imbert P, Darie H, et al. Liposomal amphotericin B treatment of cutaneous leishmaniasis contracted in Djibouti and resistant to meglumine antimoniate. Bull Soc Pathol Exot. 2003;96(3): 209-211.

40. Yardley V, Croft SL. A comparison of the activities of three amphotericin B lipid formulations against experimental visceral and cutaneous leishmaniasis. Int J Antimicrob Agents. 2000;13(4):243-248.

41. Lightburn E, Morand JJ, Meynard JB, et al. Management of American cutaneous leishmaniasis. Outcome apropos of 326 cases treated with high-dose pentamidine isethionate. Med Trop (Mars). 2003;63(1): $35-44$.

42. Andersen EM, Cruz-Saldarriaga M, Llanos-Cuentas A, et al. Comparison of meglumine antimoniate and pentamidine for peruvian cutaneous leishmaniasis. Am J Trop Med Hyg. 2005;72(2):133-137.

43. Soto J, Rea J, Balderrama M, et al. Efficacy of miltefosine for Bolivian cutaneous leishmaniasis. Am J Trop Med Hyg. 2008;78(2):210-211.

44. Soto J, Arana BA, Toledo J, et al. Miltefosine for new world cutaneous leishmaniasis. Clin Infect Dis. 2004;38(9):1266-1272.

45. Jolliffe DS. Cutaneous leishmaniasis from Belize - treatment with ketoconazole. Clin Exp Dermatol. 1986;11(1):62-68.

46. Franke ED, Wignall FS, Cruz ME, et al. Efficacy and toxicity of sodium stibogluconate for mucosal leishmaniasis. Ann Intern Med. 1990; 113(12):934-940.
47. Amato VS, Tuon FF, Imamura R, Abegao de Camargo R, Duarte MI, Neto VA. Mucosal leishmaniasis: description of case management approaches and analysis of risk factors for treatment failure in a cohort of 140 patients in Brazil. J Eur Acad Dermatol Venereol. 2009;23(9): 1026-1034.

48. Oliveira-Neto MP, Mattos M, Pirmez C, et al. Mucosal leishmaniasis ("espundia") responsive to low dose of N-methyl glucamine (Glucantime) in Rio de Janeiro, Brazil. Rev Inst Med Trop Sao Paulo. 2000; 42(6):321-325.

49. de Oliveira-Neto MP, Mattos Mda S. Successful therapeutic response of resistant cases of mucocutaneous leishmaniasis to a very low dose of antimony. Rev Soc Bras Med Trop. 2006;39(4):376-378.

50. Amato VS, Tuon FF, Bacha HA, Neto VA, Nicodemo AC. Mucosal leishmaniasis. Current scenario and prospects for treatment. Acta Trop. 2008;105(1):1-9.

51. Amato VS, Tuon FF, Camargo RA, Souza RM, Santos CR, Nicodemo AC. Can we use a lower dose of liposomal amphotericin B for the treatment of mucosal American leishmaniasis? Am J Trop Med Hyg. 2011;85(5):818-819.

52. Soto J, Toledo J, Valda L, et al. Treatment of Bolivian mucosal leishmaniasis with miltefosine. Clin Infect Dis. 2007;44(3):350-356.

53. Soto J, Rea J, Valderrama M, et al. Efficacy of extended (six weeks) treatment with miltefosine for mucosal leishmaniasis in Bolivia. Am J Trop Med Hyg. 2009;81(3):387-389.

54. Brazil. Ministry of Health. Secretary of Health Surveillance. Guideline on Surveillance of American Tegumentary Leishmaniasis. 2nd ed. Brasília: Publisher: Ministry of Health, 180 p. 2010. Available at: portal. saude.gov.br/portal/arquivos/pdf/manual_lta_2ed.pdf

55. Cruz I, Nieto J, Moreno J, Canavate C, Desjeux P, Alvar J. Leishmania/ HIV co-infections in the second decade. Indian J Med Res. 2006;123(3): 357-388.

56. Alvar J, Canavate C, Gutierrez-Solar B, et al. Leishmania and human immunodeficiency virus coinfection: the first 10 years. Clin Microbiol Rev. 1997;10(2):298-319.

57. Rabello A, Orsini M, Disch J. Leishmania/HIV co-infection in Brazil: an appraisal. Ann Trop Med Parasitol. 2003;97 Suppl 1:17-28.

58. Alvar J, Aparicio P, Aseffa A, et al. The relationship between leishmaniasis and AIDS: the second 10 years. Clin Microbiol Rev. 2008;21(2):334-359, table of contents.

59. Ritmeijer K, ter Horst R, Chane S, et al. Limited effectiveness of highdose liposomal amphotericin B (AmBisome) for treatment of visceral leishmaniasis in an Ethiopian population with high HIV prevalence. Clin Infect Dis. 2011;53(12):e152-e158.

60. Hailu W, Weldegebreal T, Hurissa Z, et al. Safety and effectiveness of meglumine antimoniate in the treatment of Ethiopian visceral leishmaniasis patients with and without HIV co-infection. Trans $R$ Soc Trop Med Hyg. 2010;104(11):706-712.

61. Ritmeijer K, Dejenie A, Assefa Y, et al. A comparison of miltefosine and sodium stibogluconate for treatment of visceral leishmaniasis in an Ethiopian population with high prevalence of HIV infection. Clin Infect Dis. 2006;43(3):357-364.

62. Sinha PK, van Griensven J, Pandey K, et al. Liposomal amphotericin B for visceral leishmaniasis in human immunodeficiency virus-coinfected patients: 2-year treatment outcomes in Bihar, India. Clin Infect Dis. 2011;53(7):e91-e98.

63. den Boer ML, Alvar J, Davidson RN, Ritmeijer K, Balasegaram M. Developments in the treatment of visceral leishmaniasis. Expert Opin Emerg Drugs. 2009;14(3):395-410.

64. van Griensven J, Balasegaram M, Meheus F, Alvar J, Lynen L, Boelaert M. Combination therapy for visceral leishmaniasis. Lancet Infect Dis. 2010;10(3):184-194.

65. Soni P, Prasad N, Khandelwal K, et al. Unresponsive cutaneous leishmaniasis and HIV co-infection: report of three cases. Indian J Dermatol Venereol Leprol. 2011;77(2):251.

66. Guimaraes LH, Machado PR, Lago EL, et al. Atypical manifestations of tegumentary leishmaniasis in a transmission area of Leishmania braziliensis in the state of Bahia, Brazil. Trans R Soc Trop Med Hyg. 2009;103(7):712-715. 
67. Lindoso JA, Barbosa RN, Posada-Vergara MP, et al. Unusual manifestations of tegumentary leishmaniasis in AIDS patients from the New World. Br J Dermatol. 2009;160(2):311-318.

68. Guerra JA, Coelho LI, Pereira FR, et al. American tegumentary leishmaniasis and HIV-AIDS association in a tertiary care center in the Brazilian Amazon. Am J Trop Med Hyg. 2011;85(3):524-527.

69. Gomes-Silva A, de Cassia Bittar R, Dos Santos Nogueira R, et al. Can interferon-gamma and interleukin-10 balance be associated with severity of human Leishmania (Viannia) braziliensis infection? Clin Exp Immunol. 2007;149(3):440-444.

70. Ribeiro de Jesus A, Luna T, Pacheco de Almeida R, Machado PR, Carvalho EM. Pentoxifylline down modulate in vitro $T$ cell responses and attenuate pathology in Leishmania and HTLV-I infections. Int Immunopharmacol. 2008;8(10):1344-1353.

71. Machado PR, Lessa H, Lessa M, et al. Oral pentoxifylline combined with pentavalent antimony: a randomized trial for mucosal leishmaniasis. Clin Infect Dis. 2007;44(6):788-793.

72. Miranda-Verastegui C, Tulliano G, Gyorkos TW, et al. First-line therapy for human cutaneous leishmaniasis in Peru using the TLR7 agonist imiquimod in combination with pentavalent antimony. PLOS Negl Trop Dis. 2009;3(7):e491.

73. Lessa HA, Machado P, Lima F, et al. Successful treatment of refractory mucosal leishmaniasis with pentoxifylline plus antimony. Am J Trop Med Hyg. 2001;65(2):87-89.

74. Arevalo I, Ward B, Miller R, et al. Successful treatment of drugresistant cutaneous leishmaniasis in humans by use of imiquimod, an immunomodulator. Clin Infect Dis. 2001;33(11):1847-1851.
75. Falcoff E, Taranto NJ, Remondegui CE, et al. Clinical healing of antimony-resistant cutaneous or mucocutaneous leishmaniasis following the combined administration of interferon-gamma and pentavalent antimonial compounds. Trans R Soc Trop Med Hyg. 1994;88(1):95-97.

76. Almeida R, D’Oliveira A Jr, Machado P, et al. Randomized, doubleblind study of stibogluconate plus human granulocyte macrophage colony-stimulating factor versus stibogluconate alone in the treatment of cutaneous Leishmaniasis. J Infect Dis. 1999;180(5):1735-1737.

77. Coler RN, Goto Y, Bogatzki L, Raman V, Reed SG. Leish-111f, a recombinant polyprotein vaccine that protects against visceral Leishmaniasis by elicitation of CD4+ T cells. Infect Immun. 2007;75(9):4648-4654.

78. Badaro R, Lobo I, Munos A, et al. Immunotherapy for drug-refractory mucosal leishmaniasis. J Infect Dis. 2006;194(8):1151-1159.

79. Convit J, Ulrich M, Zerpa O, et al. Immunotherapy of American cutaneous leishmaniasis in Venezuela during the period 1990-1999. Trans $R$ Soc Trop Med Hyg. 2003;97(4):469-472.

80. Gonzalez U, Pinart M, Rengifo-Pardo M, Macaya A, Alvar J, Tweed JA. Interventions for American cutaneous and mucocutaneous leishmaniasis. Cochrane Database Syst Rev. 2009;2:CD004834.

81. Tiuman TS, Santos AO, Ueda-Nakamura T, Filho BP, Nakamura CV. Recent advances in leishmaniasis treatment. Int J Infect Dis. 2011;15(8):e525-e532.

82. Miguel DC, Yokoyama-Yasunaka JK, Uliana SR. Tamoxifen is effective in the treatment of Leishmania amazonensis infections in mice. PLoS Negl Trop Dis. 2008;2(6):e249.
Research and Reports in Tropical Medicine

\section{Publish your work in this journal}

Research and Reports in Tropical Medicine is an international, peerreviewed, open access journal publishing original research, case reports, editorials, reviews and commentaries on all areas of tropical medicine, including: Diseases and medicine in tropical regions; Entomology; Epidemiology; Health economics issues; Infectious disease; Laboratory

\section{Dovepress}

science and new technology in tropical medicine; Parasitology; Public health medicine/health care policy in tropical regions; and Microbiology. The manuscript management system is completely online and includes a very quick and fair peer-review system. Visit http://www.dovepress. com/testimonials.php to read real quotes from published authors. 